\title{
ATENDIMENTO PSICOLÓGICO EM AMBIENTE UNIVERSITÁRIO: uma experiência de acolhimento das demandas psicopedagógicas
}

DOI: 10.22289/2446-922X.V7N2A5

\author{
Diogenes Antonio Pascini Ribeiro ${ }^{1}$ \\ Gilmar Antoniassi Junior
}

\section{RESUMO}

O presente artigo tem por objetivo relatar a experiência vivenciada pelo graduando em psicologia nos anos de 2017 e 2018, atuando em um Núcleo de Atendimento Psicopedagógico que foi ofertada em instituição privada do ensino superior. O relato faz um apanhado da reflexão acerca da implementação da proposta do apoio emocional e educacional no ambiente universitário. Foi possível perceber por meio do trabalho desenvolvido através do Núcleo de Atendimento Psicopedagógico o quanto os universitários necessitam de um suporte para as diferentes demandas da vida pessoal que refletem no ambiente universitário.

Palavras-chave: Psicologia Clínica; Universitários; Experiência.

\section{PSYCHOLOGICAL SERVICE IN A UNIVERSITY ENVIRONMENT: an experience of welcoming psychopedagogical demands}

\section{ABSTRACT}

This article aims to report the experience lived by the graduate student in psychology in the years 2017 and 2018, working in a psychopedagogical service center that was offered in a private higher education institution. The report summarizes the reflection on the implementation of the proposal for emotional and educational support in the university environment. It was possible to perceive through the work developed through the Center for Psychopedagogical Assistance how much the university students need support for the different demands of personal life that reflect in the university environment.

Keywords: Clinical Psychology; College Students; Experience.

\section{ATENCIÓN PSICOLÓGICA EN UN ENTORNO UNIVERSITARIO: una experiencia acogedora al graduarse}

\footnotetext{
${ }^{1}$ Endereço eletrônico de contato: diogenes.pascini.psicologo@gmail.com

Recebido em 06/01/2021. Aprovado pelo conselho editorial para publicação em 21/07/2021.
} 


\section{RESUMEN}

El propósito de este artículo es reportar la experiencia vivida por el estudiante de posgrado en psicología en los años 2017 y 2018, trabajando en un Centro de Servicios Psicopedagógicos que se ofreció en una institución privada de educación superior. El informe resume la reflexión sobre la implementación de la propuesta de apoyo emocional y educativo en el ámbito universitario. Se pudo percibir a través del trabajo desarrollado a través del Centro de Asistencia Psicopedagógica cuánto los estudiantes universitarios necesitan apoyo para las diferentes demandas de la vida personal que se reflejan en el ámbito universitario.

Palabras clave: Psicología Clínica; Estudiantes Universitarios; Experiencia.

\section{INTRODUÇÃO}

O atendimento psicológico dispõe de referencial e potencial para desenvolver seu trabalho científico sobre relações humanas, buscando compreender destas como se organizam nos cenários e ao longo do tempo, e quais fatores interferem em suas dinâmicas. O ambiente universitário, como um todo, abarca contextos que se interligam e influenciam diretamente na sustentação do que chamamos de mundo acadêmico. Sendo assim, estes constituem a globalidade a partir da conexão de nuances acadêmicas, sociais, pessoais e vocacionais ao passo que estas facetas coadunam entre si e criam a atmosfera universitária (Ogushi \& Bardagi, 2015).

Neste cenário os relacionamentos interpessoais, bem como questões individuais são colocados à luz de um novo rigor para a formação de um profissional que se instituirá pela égide de vocação, instrumentalização e principalmente pela adequação aos novos requisitos que caracterizam o ensino superior (Ogushi \& Bardagi, 2015, p. 36).

Assim, a transição para a vida universitária é complexa e exige do graduando um amplo conjunto de habilidades para lidar com as diferentes exigências que lhes são apresentadas, em geral quando este ainda é um jovem, em processo de formação. (Ramos, 2018, p. 58).

Segundo o Ministério da Economia [Brasil] (2019, p. 12) entre os anos 2011 a 2014, percebeu-se aumento significativo de egressos em instituições de ensino superior de nosso país, substancialmente nas instituições particulares, quando o custeio de mensalidades passou a ser financiado por políticas públicas para a educação, principalmente através do programa de financiamento estudantil (FIES). Um dos fatores que impulsionou o aumento da quantidade e contratos foi a realocação do risco dos contratos estabelecidos entre as instituições de ensino e um fundo garantidor firmado pelo governo, com isso alunos que não tinham fiador tiveram o acesso viabilizado pelo Novo FGEDUC - Fundo De Garantia De Operações De Crédito Educativo (BRASIL, 2019, p. 59). 
Novas propostas de acesso ao ensino superior viabilizaram acesso a um novo público, formado em sua maioria por jovens, e assim diversificou o cenário acadêmico. Em informações coletadas em (Brasil, 2019, p. 17), no ano de 2010 cerca de 65,4\% das vagas do FIES estavam destinadas a estudantes de até 24 anos e em porcentagem de $77,4 \%$ no primeiro semestre de 2017 , o que indica que a cada ano o ingresso de estudantes no ensino superior tende a ocorrer com maior frequência no início da adultez, expressivamente estudantes com entre 18 e 25 anos de idade.

Tais dados expressam a amplitude dos egressos do ensino superior, público que possivelmente encontrará dificuldades com a mudança no rigor do contexto estudantil, tais modificações serão as possíveis causadoras de estresse e estranhamento por parte dos estudantes (Regina, 2016, p. 116).

O ambiente acadêmico deve então, fazer o papel mediador diante de demandas que o aluno apresente nas questões acadêmicas para orientá-lo a procurar serviço condizente para sua saúde mental, pois muitos conflitos sugerem um pedido de ajuda feito de maneira silenciosa, conforme (Cerioni \& Herzberg, 2016, p. 598) "ligar em um serviço, se inscrever para atendimento psicológico caracterizam um pedido de ajuda".

Com isso, é compreensível a necessidade de intervenções psicológicas junto ao público adolescente para que consigam lidar com o sofrimento psíquico suscitado nessa etapa de vida. $A$ psicoterapia poderia, a partir de suas diferentes modalidades, desempenhar um papel na promoção da saúde mental/emocional desses jovens (Sei \& Zuanazzi, 2016, p. 91).

Assim, toda vivencia "terapêutica" exige mobilização de forças internas, principalmente àqueles que se encontram em estado peculiar de desenvolvimento.

Desta forma, o tratamento efetiva-se a partir de oscilações permanentes entre refúgios e saídas, e objetiva favorecer identificações estruturantes, ou seja, auxiliar o adolescente na construção de uma identidade própria, autêntica, íntegra e não mais existir através de identificações alienantes. (Jordão, 2008, p. 170).

Compreende-se o aumento de egressos de várias faixas etárias, se veem incumbidos de cumprir as exigências nas universidades, que pelo rigor provocam evasões, por: desligamento; por desistência ou abandono, retenção, jubilamento, ou outro motivo (Sales, 2013, p. 22).

Estar atento às expectativas pode ajudar o entrevistador a acessar o desejo inconsciente, permitindo assim uma compreensão maior e uma aproximação com o sofrimento da pessoa que busca ajuda. Escutar as expectativas não significa necessariamente satisfazê-las, mas compreendêlas, legitimá-las e auxiliar o paciente a se apropriar delas, elaborando em certa medida, o quanto é possível e necessário fazer. (Cerioni \& Herzberg, 2016, p.605). 
Para tanto, o objetivo deste artigo é relatar a experiência vivenciada pelo graduando em psicologia nos anos de 2017 e 2018, atuando em um núcleo de atendimento psicopedagógico que ofertou cuidados aos alunos de uma instituição privada do ensino superior: Faculdade Patos de Minas (FPM) situada em Patos de Minas, cidade do interior do estado de Minas Gerais.

\section{MATERIAIS E MÉTODOS}

Trata-se de um estudo descritivo, qualitativo, do tipo relato de experiência, com a finalidade de integrar conhecimentos teóricos trazendo a compreensão da experiencia de um graduando em psicologia que participou do Núcleo de Apoio Psicopedagógico que visava atender demandas que imergiam nos campi da Faculdade Patos de Minas, mais precisamente no ano de 2017 e durante 0 segundo semestre de 2018.

Realizou-se a busca de arquivos enviados via e-mail, anotações feitas em sessões de supervisão, bem como de relatórios mensais e anuais que foram feitos e remetidos a supervisora do projeto e assim constitui-se a base de dados. Para a elaboração desse trabalho foi necessário relembrar vivencias, sentimentos despertados, casos atendidos, dúvidas compartilhadas, sessões de supervisão e muitas destas informações foram rememoradas na construção deste trabalho acadêmico.

\section{RELATO DA EXPERIENCIA}

O ingresso no ensino superior representa um grande desafio, pela complexidade dos conteúdos, por ser uma nova etapa da vida, também pela diversidade do público estudantil e consequentemente pelas demandas diversas que eclodem em salas de aulas e corredores.

Devido a variedade de cursos ofertados na IES (Instituição de Ensino Superior), cada qual com suas especificidades, acumulou-se diariamente reclamações de comportamentos disfuncionais para os coordenadores, que ao perceberem conteúdos conflitantes no âmbito acadêmico se puseram a pensar em meios de acolher tais demandas, para tanto criou-se o NUAP (Núcleo de Atendimento Psicopedagógico).

O motivo de integrar este projeto foi adquirir interesse em adquirir prática clínica, visto a possiblidade de atuar adquirindo conhecimento acerca da profissão, com ênfase voltada a demandas psicopedagógicas. Para acolher as demandas contaríamos com a supervisão.

Não se tratava de uma proposta do estágio psicanalítico, a proposta é de um núcleo de atendimento psicológico voltado para questões psicopedagógicas. Para tanto contávamos com atuação de supervisora cuja formação e atuação clínica fundamenta-se na psicanálise. A formação para o atendimento psicanalítico provém de curso de formação, o qual não tínhamos, mas enquanto graduandos em psicologia ofertávamos uma escuta que considera aspectos relacionados ao 
inconsciente, material de trabalho primordial as psicoterapias que compreendem questões da ordem do inconsciente.

De modo a garantir a ética e sigilo vou citar todos os envolvidos nos relatos com o substantivo no gênero masculino, de maneira uniforme para respeitar e resguardar a identidade dos pacientes.

O NUAP buscou se estruturar para que os atendimentos pudessem ocorrer resguardando os pacientes de exposição e garantindo-Ihes discrição devida. Vale um adendo sobre este tópico, pois, a clínica escola do curso de psicologia ofertava atendimentos à sociedade, acessível a todos seus estudantes, mas convencionou-se que um serviço de atendimentos focado justamente no público dos próprios estudantes poderia ser fortuito, atuando em um viés interessado em questões psicopedagógicas, evitando a circulação e permanência de estudantes na sala de espera de atendimentos da clínica escola da faculdade de psicologia da Faculdade Patos de Minas. Desta forma, a clínica escola disponibilizaria horários preenchidos por alunos desta IES e assim ofertaria mais horários para os atendimentos da sociedade em geral, além de que para os graduandos de psicologia dos últimos períodos serem atendido por um colega de sala pode inviabilizar o vínculo terapêutico.

Em supervisões fomos orientados de que podem ocorrer situações de contato com pacientes fora do ambiente de atendimento psicológico e que situações destas ensejam posicionamento assertivo e respeitoso, de modo a manter o vínculo terapêutico (rapport) seguro.

Por mais que nossa discrição tenha sido mantida, ocorreram situações que serviram de aprendizado sob como lidar com situações adversas, recebíamos orientações em sessões de supervisão acerca de como primar pela postura de confidencialidade, ética e sigilo. Particularmente, eu pude compreender que a atuação do psicólogo incumbe renúncia de algumas questões em favor do profissionalismo. Por exemplo, em espaços de convívio coletivo em um campus que abriga vários cursos, praças de alimentação, bibliotecas, ou no deslocamento diário, em várias outras situações corriqueiras a conduta assertiva do profissional é o diferencial e garantidor de preceitos profissionais.

É inevitável "se esbarrar" por aí com pacientes! Já evitar que os pacientes em suas demandas não se sintam invadidos ou expostos (mesmo que não haja motivos para eles se sentirem assim), é nosso dever profissional, e de toda maneira, resguardar-se de interpretações que os distanciem dos atendimentos é uma postura de continência.

Sobre a logística, buscou-se salas discretas para se instalar o NUAP, evitando assim expor pacientes em locais de muito movimento, em contrapartida pensava-se também na segurança de nós estagiários que atenderíamos pessoas com sofrimentos psíquicos e condições variadas, e que poderiam também nos colocar em situações de risco e perigo. Particularmente compreendi ao longo de minha participação no projeto que uma sala fixa, sem alterações constantes gera maior 
segurança psíquica e garante maior adesão dos pacientes aos atendimentos. Em supervisão discutimos sobre esta e demais questões relacionadas ao setting nos conceitos psicanalíticos, que relaciona muitos outros aspectos além do espaço físico, contudo, não é do escopo deste trabalho, em virtude do espaço delimitado, por isso, não me delongarei mais sobre este tema.

Com o desenvolvimento do projeto percebeu-se a possibilidade da oferta dos atendimentos do NUAP aos professores, coordenadores dos cursos da instituição, e colaboradores de todos os setores da instituição em todos os campi universitários, mantendo-se o foco psicopedagógico dos atendimentos visando adaptações relacionais e estabelecimento de novos patamares de saúde mental aos atendidos pelo projeto.

O NUAP objetivava duas frentes de trabalho; psicoeducação, mobilizando a sensibilização, atentos às condições de atenção, cognição, raciocínio, dos níveis de consciência, a adequação interpessoal, e, também na frente de trabalho da psicologia com ênfase em questões do indivíduo; demandas pessoais, de desenvolvimento, entraves sob dinâmicas vivenciais, sentimentos adversos como: ansiedade, culpa, menos valia, projeções destrutivas e demais fatores que interferiam nos contextos acadêmicos.

Nós, estagiários do NUAP, desde o primeiro encontro tivemos a responsabilidade inerente ao projeto, ao opinar e negociar dias em que ocorreriam supervisões coletivas, na fixação de horários de atendimento, campus em que cada um atuaria, jornada de trabalho, ainda falando sobre o campus, coube a nós (estagiários) apresentarmos o projeto sala por sala aos alunos dos cursos, esclarecendo nossa proposta e fazendo esse primeiro contato com público potencial (estudantes universitários), todos os coordenadores já estavam informados de nosso projeto através de comunicação interna da instituição (FPM).

Em uma das primeiras sessões de supervisão recebemos orientação para apresentarmos aos colaboradores da instituição e informarmos acerca do nosso projeto, e também para justificar nossa presença, e a de pacientes, e também demonstrarmos nossa disposição para acolhê-los caso sentissem necessidade.

Sobre a supervisão, desde o início do NUAP a supervisora demonstrou-se inclinada pela busca de uma oferta de escuta diretiva às nossas dúvidas enquanto estagiários, nos orientou quanto às maneiras mais adequadas e fortuitas de interação com os pacientes, e sempre que identificava mobilizações e conteúdos particulares ao relatarmos os casos nos propunha reflexões para que percebêssemos a dinâmica de envolvimento que nossos próprios relatos sinalizavam.

Destaco que nossa participação em sessões de supervisão era indispensável aos estagiários, e nestes encontros coletivos, recebíamos orientações e sinalizações sobre o caso que atendíamos, sob nossa percepção a respeito de nosso envolvimento nos casos atendidos, e constantemente éramos solicitados a contribuir no estudo de caso do colega ofertando reflexões. Tais sessões de supervisão ocorriam uma ou duas vezes por semana (ocorreram adequações 
quanto a periodicidade) mas na maioria das semanas nos reuníamos dois dias por semana, em sessões de supervisão com 2 a 3 horas de duração. Ocorreram sessões de supervisão extras ou até mesmo individuais, que nos eram ofertadas com generosidade de acordo com nossas mobilizações e necessidades, em tais momentos éramos sinalizados a fazer leituras e a procurar acompanhamento para nossas questões individuais de saúde mental.

Uma orientação enfatizada pela supervisora era a indicação de que para o profissional psicólogo é indispensável estar sob "análise pessoal" para assim conseguir distinguir conteúdo dos pacientes de seus conteúdos particulares. No início da atuação no NUAP percebi a necessidade de procurar atendimento para mim pela mobilização que o contato com os Outros me causou.

Ainda sobre as sessões de supervisão, complemento que para mim era fonte de muito aprendizado ouvir os relatos de outros colegas de estágio, o que viabiliza que eu identificasse nos colegas a dificuldade em lidar com erros cometidos, a evitação em expressar conteúdos que mobilizam questões pessoais e assim aprendi maneiras saudáveis de lidar com ocorrências dos atendimentos, aprendi a confiar na supervisão como fonte de aprendizado, e tenho pra mim que cometer um ato inadequado mas não reportá-lo a seu supervisor, isso sim, configura um erro.

Como forma de prestar contas de nosso trabalho fazíamos mensalmente relatórios sobre os atendimentos, seguindo três eixos básicos de relatos: sobre demandas acolhidas, sobre aprendizados enquanto estudantes de psicologia, e sobre as sessões de supervisão, e ao fim do ano fazíamos um relatório anual abarcando a experiência como um todo.

Com relação ao sigilo, fundamental na prática do psicólogo, convencionou-se a não utilizarmos de nomes ao relatarmos os casos, descrevíamos nossos pacientes apenas pela idade, sexo e curso ou função ocupada na instituição de ensino.

Eu compreendi que o primeiro atendimento (acolhimento) tem a função de identificar também questões da dinâmica de vida declarada pelo paciente, a quantidade de atendimentos semanais indicadas para o caso, condições de locomoção, e de cumprir horários fechados no contrato terapêutico. O motivo da pessoa buscar atendimento é muito importante no acolhimento, se ela está sob algum risco iminente, mas também compreender sobre a condição desta participar efetivamente do compromisso dos atendimentos é fundamental.

Ao passo que os pacientes eram acolhidos fazíamos uma triagem para identificar qual estagiário mais indicado a atender o caso, pela disponibilidade de horários, campus em que atendia, reais necessidades do paciente. Compreendi desse contrato que era firmado com os pacientes que este manejo representa empatia e respeito com os Outros, é uma forma de entender um pouco mais sobre a disponibilidade e possibilidades do paciente.

A equipe de estagiários contava com entre 4 e 6 integrantes que se organizaram nos períodos de manhã, tarde e noite. O gráfico abaixo traz informações sobre as demandas chegadas a mim sobre a distribuição feita com os demais integrantes do NUAP. 


\begin{tabular}{|c|c|c|}
\hline \multicolumn{2}{|c|}{ PANORAMA DE DEMANDAS ACOLHIDAS } \\
\hline & Ano 2017 & Ano 2018 \\
\hline Total de estudantes acolhidos & 30 & 20 \\
\hline $\begin{array}{c}\text { Total de acolhidos e encaminhados } \\
\text { ao atendimento de outro estagiário }\end{array}$ & 12 & 09 \\
\hline $\begin{array}{c}\text { Estudantes acolhidos e atendidos } \\
\text { por mim }\end{array}$ & 18 & 11 \\
\hline
\end{tabular}

Houve uma procura maior no campus onde eu estava disponível aos acolhimentos, pelo fato de que lá estavam concentrados o maior número de cursos, e, portanto, maior demanda de atendimentos.

O contato com o paciente é um momento que requer muita sutileza para escutar o dito e os não ditos, pois muitos pacientes, apresentam suspeição e desconfiança em suas falas, desconhecimento da profissão da psicologia, postura de simulação e dissimulação. A linguagem corporal oferece informações dadas pelo comportamento, o fato de se manter inquieto ou de se manifestar de maneira diferente em determinados assuntos ou temas, as falas indiretas e de conteúdos intrínsecos nas entrelinhas, enfim há muito a se perceber dos pacientes. Recordo-me do Manual de Psicopatologia de Elie Cheniaux, livro que elenca vários aspectos a serem observados e considerados em conjunto, pois um só aspecto isoladamente não me parece que faça tanto sentido, mas que junto a outros aspectos formam um todo passível de ser considerado como possibilidades.

Uma postura adotada no início do projeto que foi sendo trabalhada pela supervisora foi de que: “- É necessário ajudar os pacientes a pensar!", me lembro da seriedade que implica fazer alguma intervenção junto aos pacientes e o quanto foi producente lapidar a maneira de conduzir estas intervenções ao longo dos atendimentos. Muitos deles solicitavam opiniões ou dicas, e isso é muito delicado pois pode ser uma forma de o paciente não se haver com suas questões, de nos destituir de nossa função psicoterapêutica e transformá-la em "amizade" o que pode reduzir o vínculo a um patamar contraproducente.

Com os insights adquiridos em sessões de supervisão compreendemos nas considerações da psicanálise qual a maneira de atuar de maneira mais indicada. Revelo que uma dificuldade encontrada por nós, foi compreender como proceder uma escuta flutuante, e nesse ponto a supervisão coletiva tem o poder diferencial de propiciar que se perceba que ao relatar sobre um caso somos impactados por acontecimentos maximizados pelos pacientes, que nos levam ao crivo de julgar se é verdade ou não, se é real ou não. Já a proposta desta forma de ofertar a escuta (flutuante) enfatiza que mais importante de que o que está sendo dito é o que este paciente está indiretamente dizendo ou querendo dizer. 
Sobre este aspecto ficou bem marcado em uma determinada supervisão em que a frase “... Se foi real ou imaginado não sei!", marcou a sessão de supervisão, com certa leveza e bom humor, sem perder a objetividade do encontro, mas foi uma forma didática de nos convidar a flutuar a escuta ao ouvir o relato de outro colega. Para assim afinar nossa escuta para o que está nas entrelinhas, captar o que não foi dito, aspectos inconscientes nas falas e não ser raptado por um relato impactante que pode ser tentativa esconder ou mostrar algo deliberadamente para ofuscar outros "objetos" no discurso do paciente.

Quanto mais eu tentava me concentrar nos relatos mais essa ânsia me distanciava do que eu estava escutando, percebi que é necessário vivenciar o momento com o outro ser humano que está se expressando em busca de um alento para sofrimento psíquico.

Tenho que compartilhar aqui outro aprendizado, de que, da mesma maneira que os pacientes podem nos trazer a dúvida de algo ter sido ou não real de fato, em muitos momentos o questionamento é sobre a intenção e posicionamento do paciente. Nem sempre o paciente relata questões que são conscientes para ele, mesmo que para quem escute (não flutuante) pareça ser tão lógico, para o paciente pode ser algo que perpassa pelo simbólico e esteja distante dos significados concretos.

Me lembro de tantas vezes que fomos orientados a "ajudar os pacientes a pensarem" e por vezes ajudar o paciente a pensar é pôr a luz pensamento mais centrado no campo do real sobre questões envoltas por sentimentos impactantes, dúvidas, ansiedades ou mecanismos de defesa que atravancam a compreensão.

Percebeu-se que haviam um número expressivo de estudantes vindos de cidades menores que solicitavam atendimento, o que nos fez pensar sobre essas demandas, sobre o acesso à psicologia que tais estudantes poderiam não terem em suas localidades, e também acerca qualidade do ensino básico e médio a qual estes tiveram acesso antes de ingressarem no ensino superior.

Das queixas relacionas ao contexto universitário acolhemos muitos casos de dificuldade de relacionamento interpessoal, enfrentamento da lei simbólica, projeção destrutiva dirigida a colegas e professores, pensamentos limitantes e autodepreciativos, rejeição ao convívio em grupos, conflitos constantes e pensamentos persecutórios, dificuldades em lidar com regras e prazos, indicativos de déficits cognitivos (dislexia, raciocínio e atenção diminuída).

Dos pacientes que acompanhei nos atendimentos psicológicos pouco se percebeu de indicativos concisos de déficit de aprendizado ou outras dificuldades de ordem pedagógica. Em sua maioria apresentavam questões pessoais que implicavam em dificuldades no contexto acadêmico em razão da pessoalidade e individualidade dos pacientes. Haviam três pacientes que faziam acompanhamento com psiquiatra e que até foram mobilizados a continuar ou retomar tais cuidados com estes profissionais bem como seguir prescrições de tratamento psicofarmacológico, em razão 
de instabilidade humoral, risco de atentarem contra a vida de si e de outros. Perceber a dinâmica destes pacientes dentro de consultório reendossou a importância que psicofarmacologia tem de ser aliada aos atendimentos psicológicos, e vice-versa. Lidar com saúde mental é algo muito sério e deve preferencialmente contar com o suporte de diferentes profissões.

É de se lembrar que tivemos um apoio consistente por parte dos professores e coordenadores de curso de toda a IES, que encaminhou muitos alunos com demandas pedagógicas e vivenciais para que o NUAP acolhesse. Conforme gráfico abaixo:

\begin{tabular}{|c|c|c|c|c|}
\hline \multicolumn{4}{|c|}{ LEVANTAMENTO DAS DEMANDAS DE ACORDO COM SEXO } \\
\hline & $\mathbf{2 0 1 7}$ & $\mathbf{2 0 1 8}$ & \multicolumn{2}{|c|}{ Busca Espontânea } \\
\cline { 4 - 5 } & & & 2017 & 2018 \\
\hline Masculino & 04 & 04 & 1 & 2 \\
\hline Feminino & 14 & 07 & 4 & 5 \\
\hline
\end{tabular}

Dos estudantes muitos declararam ansiedade, o que pode até ser uma forma genérica utilizada por pacientes para se referirem às dificuldades internas encontradas.

Ao longo dos atendimentos foram sendo reveladas demandas latentes de: intolerância a frustrações, ego fragilizado, núcleos familiares disfuncionais, agressividade incontrolada, auto agressividade, tentativas de auto extermínio, indicativos de psicoses, refúgio no imaginário e fictício, neuroses conflitantes, busca de sedução de psicoterapeuta, ataques velados, sabotagem do atendimento, precárias noções de urbanidade, vitimização, além dos mecanismos de defesa.

Algo que foi sendo refinado ao logo do período de atuação no NUAP foi sobre como lidar com amor transferencial e demais investidas que os pacientes fazem em relação à função do psicoterapeuta, visto que muitos se utilizam da figura do psicólogo (sujeito suposto saber) para fantasiarem seus desejos, direcionar falas que demonstram ataques velados ou disfarçados em alegorias, figuras de linguagem ou até mesmo nos planos oníricos. Tudo isso nos exige que saibamos suportar investidas e depósitos de fantasias pois estes ensejos de satisfação dos pacientes devem ser manejados pelo profissional ao mesmo tempo em que se trabalha com 0 paciente a lidar com o sofrimento de maneira adequada.

O gráfico a seguir nos apresenta um apanhado acerca do público que demandou pelos atendimentos. Percebe-se que alunos de variados cursos viram no NUAP uma opção para cuidar de saúde mental.

\begin{tabular}{|c|c|c|}
\hline \multicolumn{3}{|c|}{ LEVANTAMENTO DAS DEMANDAS DE ACORDO COM O CURSO DO GRADUANDO } \\
\hline & Ano 2017 & Ano 2018 \\
\hline Educação Física & 05 & 03 \\
\hline
\end{tabular}

Rev. Psicol Saúde e Debate. Jul., 2021:7(2): 66-82. 


\begin{tabular}{|c|c|c|}
\hline Engenharia Civil & 04 & 03 \\
\hline Engenharia Elétrica & 02 & 01 \\
\hline Farmácia & 03 & 02 \\
\hline Gastronomia & 03 & - \\
\hline Pedagogia & 05 & 03 \\
\hline Psicologia & 08 & 07 \\
\hline Colaboradores/Professores/Coordenadores & - & 01 \\
\hline
\end{tabular}

Sobre a conduta profissional nos era sinalizada a necessidade de filtrarmos as dinâmicas dos pacientes sem sermos complacentes nem ríspidos, mas agindo de maneira delicada e bem situada em nossa função para que aos poucos os pacientes compreendessem o seu papel da psicologia e o engajamento que se espera de um paciente.

Em supervisões nos foi indicado que a escuta é uma forma de intervenção junto ao paciente, isso é bem perceptível nos primeiros atendimentos em que os pacientes "vomitam" um emaranhado de fala demonstrando necessidade de serem escutados. Essa verborreia é até mesmo esperada, mas ao longo do processo terapêutico se faz necessário retomar algumas questões desse emaranhado a fim de que o paciente possa ressignificá-las.

Mas para retomar alguns temas o profissional deve dispor de feeling, outro termo utilizado em sessões de supervisão, esse nos conscientiza sobre a sensibilidade, a percepção do termômetro emocional das sessões, e à medida em que seja possível trabalhar com os pacientes (colocá-los para trabalhar), ou pela teoria de Jacques Lacan "promover a retificação subjetiva". Este termo elucida em nossos pensamentos a importância da empatia com a dor do outro e de como proceder as intervenções ajudando os pacientes a pensar. Essa mediação é de fundamental importância, mas só é viável a partir de um vínculo bem trabalhado desde o primeiro contato com os pacientes.

Ainda sobre o feeling durante a participação do projeto NUAP compreendi que é necessário a auto percepção. Compartilho a experiência de atendimento em que percebi que fiz mais intervenções com o paciente do que de costume, eu indaguei-o mais. Por ter percebido essa dinâmica diferente no atendimento "levei pra supervisão", e ao relatar os conteúdos envolvidos, recebi indicações acerca de temas relacionados às angústias e sentimentos por mim experimentados naquela sessão.

Um outro compartilhamento sobre minha experiência do encontro com o Outro, é de uma escuta em que experimentei de determinado paciente característico pela confusão em relação aos próprios sentimentos, mas neste dia me pareceu ter relatado de maneira mais sincera e organizada suas vivências, e diferente de outros atendimentos eu fui acometido por uma sensação de extrema tristeza e solidão que acompanhou a narrativa do abandono, era um clima de solidão em cada frase. Compreendi que ser empático é diferente de confundir funções terapêuticas, neste segundo relato Rev. Psicol Saúde e Debate. Jul., 2021:7(2): 66-82. 
que eu trouxe diferencio-o do anterior porque a tristeza que percebi não estava em mim, ela estava na outra pessoa eu a "percebi e senti", no caso anterior eu confundi questões minhas com as do paciente e intervi mais na sessão de atendimento, provável contratransferência. E como de costume essas duas vivências e muitas outras foram "levadas à supervisão" a fim de receber orientações.

Compartilhando um pouco mais de meus aprendizados faço relato sobre a contratransferência, conteúdo muito relevante para a conduta psicanalítica, mas que ao meu ver devem ser consideradas por todos psicólogos. Tenho lembrança de quando estudávamos Psicologia Escolar no $3^{\circ}$ período, em que o professor por repetidas vezes utilizava a frase: 'É necessário evitar olhar tendencioso'; compreendendo que olhar tendencioso se estende a qualquer prática profissional. E via neste projeto (NUAP) o quanto lidar com o sofrimento psíquico do Outro pode nos gerar sentimentos (contratransferência).

De modo geral, das demandas que acolhi, destaco que há pacientes que apresentam entraves para fluir atendimento, principalmente nas primeiras experiências em clínica, alguns destes são metódicos, argumentam muito bem suas falas e tem uma retórica articulada, buscam assim se blindarem, por muitas vezes até expressam que não precisam de atendimento ou justificam com ataques (conscientes ou inconscientes), não compreendem portanto seus motivos de estarem ali, mas desde sua chegada até sua partida se cercam de modo a ficarem "inacessíveis".

Há de acordo com referenciais teóricos e até mesmo de nossa cultura, a simbologia de que ocupamos o lugar de "sujeito suposto saber", e que dentro de toda a significação que isso possa causar enfrentamento da função da lei representada pelo psicoterapeuta. Em sessões de supervisão coletivas fomos sinalizados a percebermos o quão frágeis estas pessoas se sentem a ponto de não compreenderem a própria dificuldade em que se encontram. Aprendi que nossa função não é provar quem está certo ou errado, mandar, ou utilizar da posição "privilegiada" no setting para inquirir ou oprimir, mas do contrário, de acolher a demanda que estes trazem e assim prepará-los (criar rapport) para aos poucos podermos "ajudá-los a pensar" e sentirem segurança para se desarmarem e assim exercermos o papel do psicoterapeuta, que dentre tantas intervenções, uma muito válida é a de responsabilizar os pacientes e emponderá-los a fazer movimentos saudáveis para saírem do sofrimento.

Uma máxima repetida em supervisão foi: "Lidar com o sofrimento do outro é algo muito sério", em forma de sinalização de que suportar demandas e dar vazão aos sentimentos de pacientes gera mobilizações em nós.

Acerca do público atendido pelo NUAP, relevo que cerca de $80 \%$ era formado por mulheres e esse dado suscita que seja feito um estudo mais aprofundado sobre questões relativas à tamanha desproporcionalidade no quesito gênero para revelar quais fatores incidem causando tal diferença. 
Durante estes meses em que atuei no NUAP percebi que enquanto as pessoas fazem parte de um processo terapêutico, as faltas, esquivas, resistências, falas veladas, ataques, dissimulações e simulações, construções de fantasias envolvendo a psicoterapia, um investimento na terapia como salvadora, desta forma ao longo das sessões vai se construindo percepções acerca dos pacientes e suas tendências, repetições, postura, apresentação e sinais de patologias também vão sendo identificados.

Por realizar atendimentos pude identificar que uma sessão em que o paciente fala muito não é sinônimo de uma sessão produtiva, e que não é a quantidade de falas, mas a qualidade, engajamento e produtividade que prediz uma fluência. Simplesmente falar muito pode ser uma estratégia (muita das vezes) inconsciente de sabotar o atendimento, falando de tudo, menos do que deve ser dito.

Ao longo de um processo terapêutico percebeu-se a diminuição do choro ao passo que se aumenta a elaboração das verbalizações, a medida em que vai se construindo maneiras de expressar sentimentos e angústia relativos a conteúdos inominados. Desta forma a verbalização é um processo de viabilizar que angústias sejam compartilhadas diminuindo tensões, pressões, culpas, e da mesma maneira o silêncio está relacionado a estes sentimentos, bem como outras maneiras de comunicar-se que também representam aspectos a serem observados em sessões de atendimento psicológico podem predizer vinculação terapêutica em que o paciente se encontra.

Um fato que merece atenção na práxis profissional é ausência dos pacientes nas sessões (absenteísmo), o que pode nos atentar quanto nossa atuação, pois tal dinâmica pode demonstrar dificuldade de vincularem-se ao processo terapêutico.

O projeto NUAP seguia o calendário acadêmico e por isso nos foi alertado para irmos aos poucos tocando no assunto junto aos pacientes acerca da aproximação do encerramento do período letivo, de modo a compreender a interrupção de atendimentos, além de que deveríamos evitar abordar temáticas de pacientes que não pudessem ser melhor trabalhadas em poucas sessões, para que não ficassem assuntos em aberto, seria (metáfora) deixar feridas sem tratamento.

A aproximação dos últimos atendimentos culminou em evasão par parte de pacientes que não chegaram a se apresentar a sessão devolutiva. Dos pacientes que se apresentaram, em sua maioria, demonstraram dificuldade em lidar com o cessamento dos atendimentos, através de falas ríspidas, que desdenhavam ou menosprezaram o período precedente de atendimentos vivenciados. Tal vivência me pôs a pensar sobre o quanto é importante perceber aspectos gerais dos pacientes durante o processo terapêutico, em especial par uma sessão devolutiva é necessária compreender sobre a tolerância a frustração, noção de redes de apoio, e de demais profissionais da saúde mental. Fomos orientados a indicar aos pacientes que casos sentissem necessidade procurassem atendimento particulares ou da saúde pública. 
A prática do psicólogo depende de sensibilidade (feeling), mas, ser sensível e se fazer próximo é diferente de ser amigo, acolher é diferente de concordar com tudo. A profissão psicologia tem um embasamento auto crítico muito presente na atuação, para que não se confunda as funções, portanto ao meu ver deve-se seguir estes parâmetros indispensáveis, para ofertar um atendimento eficiente e que abarque investimentos do paciente, e pautado em respaldo teórico que promova movimentos producentes por parte do paciente.

Ainda que estivéssemos em um estágio e vislumbrando mais sobre a atuação do psicólogo, experienciei a noção de que deva haver referenciamento ético e técnico para suportar investidas dos pacientes. Estes podem geram desconforto até mesmo sem saber, outros agem assim intencionalmente, pois somos "local" de investimentos. Sejam por: angústias de desamparo, de solidão, sentimentos de não pertencimento, sinais de depressão e apatia, dificuldade e desinteresse de relacionamento interpessoal, conflitos relacionados à percepção/concepção/elaboração de sentimentos, precariedade de sentimentos primários, posicionamentos projetivos de aspectos negativos em pessoas e instituições, sentimento de culpa, indícios de pensamento persecutório, paranoico, hiper emotividade enfatizada pelos pacientes, entre vários outros modos de interação disfuncionais.

Numa das primeiras sessões de determinado paciente, este relatou constantemente se imaginar matando pessoas, diante disso eu não sabia se era um investimento, uma maneira de querer me assustar, enfim, busquei me manter o mais calmo possível para não transparecer o quanto me senti inseguro naquela situação. Busquei investigar sobre a possibilidade de que algo sério pudesse realmente ocorrer, qual o nível de realidade na fala do paciente, e embora houvesse uma mochila bem próxima de seus pés (o que me deixou em alerta) conduzi o atendimento até o costumeiro encerramento. Confesso que não há como não se sentir sob ameaça em uma situação dessa, mas vi a escuta como maneira de identificar a viabilidade e necessidade de se proteger sem tomada de decisão precipitada. Compreendi que aquele relato era cabal no sentido de que o paciente realmente necessitava de uma escuta para se organizar melhor em relação a suas angústias, medos, inseguranças e intolerância às frustrações.

Durante este mês de outubro de 2017, na semana conhecida como "semana do saco cheio", como de costume aqui na região de Patos de Minas não houveram aulas, e foi muito marcante o não comparecimento de pacientes, destes, alguns poucos informaram previamente a ausência, outros não compareceram na semana anterior também e nem na semana seguinte, outros já se ausentaram porque os ônibus intermunicipais fretados para o transporte estudantil não fariam viagens, já outros pacientes não se ausentavam das sessões marcadas.

Relato que nesta semana de recesso, determinado estudante, caracterizado por variadas dificuldades relacionais e acadêmicas, se fez presente para atendimento, mesmo após ter sido apanhado pela chuva, em pontualidade costumeira, chegou e solicitou alguns minutos para poder 
se ajeitar antes de ser atendido. Em outro atendimento o mesmo paciente cogitava ser atendido as 6 horas da manhã e assim conciliar os atendimentos psicopedagógicos com uma nova oportunidade de emprego que estava a negociar. Este paciente representa o engajamento de quem estava percebendo o sentido do acompanhamento psicoterapêutico e falando especificamente sobre este, relato que o mesmo apresentou grande evolução na proposta do NUAP.

Um outro aspecto que fez sentido para mim perceber é sobre horários, mas só ser pontual não indica engajamento, é mais que isso. Ocorrem variações no comparecimento dos pacientes, as vezes começam a ocorrer atrasos, que podem ir se intensificando e passando de minutinhos a dezenas de minutos, e essas variações é que são indicadores de que algo possa estar dificultando o comparecimento do paciente, talvez uma busca inconsciente de "adiar" sua chegada, da mesma forma do contrário, a antecipação ou pressa em chegar/adentrar para o atendimento podem trazer informações através do não dito. Essas questões se ligam com o feeling que estabelece a relação, e sessão após sessão vai se construindo algum sentido.

Estendendo um pouco mais sobre pontualidade, horários, relato que tive dificuldade em fazer estas intervenções com os pacientes, pois para mim era como "cobrar presença ou pontualidade" dos pacientes, mas participando do NUAP ressignifiquei esta minha dificuldade e passei a ver uma objetividade em conversar sobre isso com pacientes tendo uma visão diferente sobre pontualidade e sem me sentir estar sendo indiscreto, e consegui fazer isso com naturalidade.

Lidar com pacientes refere-se a abarcar resistências e fantasias por questões do sexo do profissional que irá atender a demanda, muito comum haver predileção ou evitação ao procurar a escuta. Pudemos acompanhar o desenvolvimento de pacientes que apresentaram estas queixas ao serem acolhidos, e identificamos na teoria psicanalítica, que há questões relacionadas a conteúdos inconscientes sobre figuras simbólicas e funções maternas/paternas que desenvolvem estas barreiras relacionais em pacientes e que isso reflete em vários contextos da vida, conjugal, profissional, acadêmica, social.

Ao longo destes meses em atuação em atendimento psicológico com ênfase em demandas psicopedagógicas e atuando sob supervisões pude vivenciar, relatar e ouvir acerca de situações das mais corriqueiras às mais complexas e confusas de serem compreendidas, casos de pacientes ponderados e inclinados ao tratamento aos casos de pacientes deslocados da realidade e avessos ao vínculo.

\section{CONSIDERAÇÕES FINAIS}

Durante os 3 semestres em que participei do NUAP estive em contato com o universo acadêmico e pude observar e vivenciar sobre atendimentos psicológicos, desde a marcação de Rev. Psicol Saúde e Debate. Jul., 2021:7(2): 66-82. 
sessão de acolhimento até entrevista devolutiva. Percebi o quanto os universitários necessitam de suporte para as demandas refletidas no contexto, muitas das vezes reflexos da vida pessoal.

Ademais, compartilhei momentos interativos com outros colegas no grupo de supervisão coletiva e tenho para mim que isso amplia as possibilidades de entendimento neste contexto de graduação. Momentos de aperfeiçoamento do cuidar do outro, além de ser um espaço efetivo para discussões teóricas. As sessões de supervisão coletivas nos proporcionaram a percepção de o quanto os mecanismos de defesa atuam (em nós) nos impedindo de perceber quando estamos imersos em enredos de contratransferências, e que é necessária uma visão externa para indicar as dinâmicas envolvidas, o nome disso é supervisão profissional.

Estagiando aprendíamos a cada semana, a cada dia, a cada sessão de atendimento, aprendíamos principalmente a buscarmos postura e conduta mais assertivas junto ao público demandante no espaço de atendimento e demais dependências por onde transitávamos diariamente.

Encontra-se poucos artigos sobre propostas de estágio nos quais a abordagem seja psicanalítica, ou sobre propostas destas feitas enquanto graduação, o que torna relevante 0 compartilhamento da vivencia de tal projeto, das dificuldades e desafios encontrados bem como dos aprendizados logrados.

Esses detalhes do manejo diário são indispensáveis para uma prática profissional assertada e promissora. Ao meu ver há ensinamentos que livros não são capazes de publicar, mas a supervisão de um profissional qualificado é capaz de intervir propondo reflexões e comedimento.

Extremamente relevante é a importância de existir propostas desta magnitude em ambiente universitários, e de o quanto é necessário aos psicólogos estarem sob supervisão não só no início de carreira, mas também ao longo de toda uma trajetória profissional. Há um público nos corredores das faculdades que grita por ajuda, muitas das vezes em silencio profundo, e as instituições devem abrir para acolher tais demandas. Este trabalho pautou-se em relatar experiencia vivida e em trazer dados a respeito de público atendido, de modo a fomentar a relevância desse serviço prestado e servir para que futuros trabalhos possam identificar fatores em comum acerca de público universitário demandante, sexo dos estudantes, faculdade cursada, entre outros aspectos que apontem questões problemas.

Concluo que o diploma confere a graduação ao profissional, mas que independente da abordagem buscada os estudos continuados, a análise particular e a supervisão profissional são indispensáveis para que o profissional mantenha-se prestando serviço técnico, científico e de qualidade e respeito aos pacientes/clientes.

\section{REFERÊNCIAS}


Brasil. Ministério da Economia. Relatório de Avaliação ao TCU 2017: FIES. Disponível em: https://www.gov.br/economia/pt-br/acesso-a-informacao/participacao-social/conselhos-eorgaos-colegiados/cmap/publicacoes/subsidios-da-uniao/avaliacaotcu/avaliacao_fies_jan2018_coef.pdf/view. Acessado em 07/11/2020.

Cerioni, R. A. N., \& Herzberg, E. (2016). Expectativas de pacientes acerca do Atendimento Psicológico em um Serviço-Escola: da Escuta à Adesão. Psicologia: Ciência e Profissão, 36(3), 597-609.

Jordão, Aline Bedin. (2008). Vínculos familiares na adolescência: nuances e vicissitudes na clínica psicanalítica com adolescentes. Aletheia, (27), 157-172. Recuperado em 08 de novembro de 2020, de http://pepsic.bvsalud.org/scielo.php?script=sci_arttext\&pid=S1413$03942008000100012 \& \operatorname{lng}=$ pt\&tlng=pt.

Ogushi, M. M. P., \& Bardagi, M. P. (2015). Reflexões sobre a relação estudante-universidade a partir de uma experiência de atendimento em orientação profissional. Extensio: Revista Eletrônica de Extensão, 12(19), 33-50.

Ramos, F. P., Jardim, A. P., Gomes, A. C. P., \& Lucas, J. N. (2018). Desafios na trajetória acadêmica e apoio psicológico ao estudante universitário: contribuições de dois Projetos de Extensão. Revista Guará, 6(9).

Pires, R. (2016). Caracterização da clientela de um programa de atendimento psicológico a estudantes universitários. Psicología, Conocimiento y Sociedad, 6(1), 114-130.

Sales, J. S. Jr. (2013). Uma análise estatística dos fatores de evasão e permanência de estudantes de graduação presencial da UFES (Doctoral dissertation, Dissertação (Mestrado Profissional em Gestão Pública)-Centro de Ciências Jurídicas e Econômicas, Universidade Federal do Espírito Santo).

Sei, M. B., \& Zuanazzi, A. C. (2016). A clínica psicanalítica com adolescentes: considerações sobre a psicoterapia individual ea psicoterapia familiar. Psicologia Clínica, 28(2), 89-108. 